\title{
Uma Interpretação Molar da Dor Crônica na Fibromialgia
}

\author{
Bruna de Souza \\ Universidade Estadual de Maringá, \\ Maringá, PR, Brasil.
}

\author{
Carolina Laurenti \\ Universidade Estadual de Maringá, \\ Maringá, PR, Brasil.
}

\begin{abstract}
Resumo:A fibromialgia (FM) éuma síndrome reumatológica caracterizada por dor crônica de etiologia desconhecida, configurando-se como uma problemática teórico-prática na área da saúde. A Análise do Comportamento pode contribuir com o estudo desta síndrome, possibilitando uma análise funcional da dor crônica, em termos das possíveis variáveis contextuais relacionadas à sua origem e manutenção no âmbito da FM. Considerando isso, esta pesquisa empírico-exploratória objetivou operacionalizar a dor crônica na FM em termos de contingências. Para tanto, a análise das contingências foi orientada por uma perspectiva molar, investigando a dor como uma classe de comportamentos constituída ao longo da história de vida do indivíduo. Para obtenção das informações, foram realizadas entrevistas semiestruturadas com oito mulheres diagnosticadas com FM que frequentavam um hospital universitário no estado do Paraná. As informações foram sistematizadas e interpretadas à luz dos conceitos da Análise do Comportamento. Os resultados indicam que a dor crônica na FM é uma classe comportamental, envolvendo elementos respondentes (mobilização biológica à resposta de estresse e resposta nociceptiva) e operantes (reclamações, absenteísmo no trabalho, isolamento social). Além disso, essa classe tem como antecedentes situações de incontrolabilidade e de limitação corporal, e, como consequências: atenção social e evitação tanto da reprovação social quanto da realização malfeita de tarefas. Esses resultados complementam a literatura analítico-comportamental nacional sobre a FM; fornecem subsídios teóricos para a elaboração de tratamentos psicoterápicos, bem como para o manejo da relação médico-paciente, de modo a torná-la mais efetiva.
\end{abstract}

Palavras-chave: Fibromialgia, Dor, Análise Funcional.

\section{Molar Interpretation of Chronic Pain in Fibromyalgia}

\begin{abstract}
Fibromyalgia (FM) is a rheumatologic syndrome characterized by chronic pain of unknown etiology, configured as a theoretical and practical issue in the Health area. Behavior Analysis can contribute to the study of this syndrome by providing a functional analysis of chronic pain, in terms of possible contextual variables related to its origin and maintenance in FM. Taking that into consideration, this empirical and exploratory project aimed to operationalize the chronic pain in FM in terms of contingencies. For this, the analysis of contingencies was guided by a molar perspective, investigating pain as a class of behavior constituted throughout the life history of the individual. To obtain the information, semi-structured interviews were conducted with eight women diagnosed with FM who attended a University Hospital in the state of Paraná. The information was systematized and interpreted in light of Behavior Analysis concepts. The results indicate that chronic pain in FM is a behavioral class, involving respondent (biological mobilization to stress response and nociceptive response) and operant (complaints, absenteeism at work, social isolation) elements; in addition, this class has as background conditions of uncontrollability and bodily limitation, and as consequences: social care, and avoidance of both social disapproval and poorly-executed tasks. These results complement the national behavior-analytic literature on FM; they also provide theoretical support for the development of psychotherapeutic treatments, as well as contribute to the effectiveness of the doctor-patient relationship in the context of FM.
\end{abstract}

Keywords: Fibromyalgia, Pain, Functional Analysis. 


\title{
Una Interpretación Molar del Dolor Crónico en la Fibromialgia
}

\begin{abstract}
Resumen: La fibromialgia (FM) es un síndrome reumatológico caracterizado por dolor crónico de etiología desconocida, que se configura como una problemática teórico-práctica en el área de la salud. El Análisis de la Conducta puede contribuir para el estudio de tal síndrome, posibilitando un análisis funcional del dolor crónico, en términos de las posibles variables contextuales relacionadas a su origen y mantenimiento en el ámbito de la FM. Con tal consideración, esta investigación empírica-exploratoria objetivó operacionalizar el dolor crónico en términos de contingencias. Para eso, la interpretación de las contingencias se ha guiado por una óptica molar de análisis, que investiga el dolor como una clase de comportamiento formada a lo largo de la historia de vida del individuo. Para obtención de las informaciones, se hicieron entrevistas semiestructuradas con ocho mujeres diagnosticadas con FM que frecuentaban un hospital universitario en el estado de Paraná. Las informaciones fueron sistematizadas e interpretadas a la luz de los conceptos del Análisis de la Conducta. Los resultados indican que el dolor crónico en la FM es una clase conductual, que envuelve elementos respondientes (la movilización biológica a la respuesta al estrés y respuesta nociceptiva) y operantes (quejarse, no ir más al trabajo, aislarse). Además, tal clase tiene como antecedentes situaciones de ausencia de control y limitación corporal, y como consecuencias: la atención social, y evitar tanto la reprobación social como la mala realización de tareas. Esos resultados complementan la literatura analítico-conductual nacional sobre la FM; y proveen subsidios teóricos para la elaboración de tratamientos psicoterápicos, así como para el manejo de la relación médico-paciente, de manera a que esta sea más efectiva.
\end{abstract}

Palabras clave: Fibromialgia, Dolor, Análisis Funcional.

\section{Introdução}

A fibromialgia (FM) é uma síndrome reumatológica caracterizada principalmente pelo aumento da sensibilidade dolorosa em vários pontos do corpo, denominados tender points (Brandt et al., 2011). Além da dor musculoesquelética, há outros sintomas, sendo os mais comuns: distúrbio do sono, rigidez matinal, fadiga, ansiedade e depressão (Helfenstein Júnior, Goldenfum, \& Siena, 2012). Essa síndrome acomete principalmente a população feminina na faixa etária de 36 a 60 anos (Cavalcante et al., 2006), incidindo em até 5\% da população mundial (Braz, Paula, Diniz, \& Almeida, 2011) e 2\% da população brasileira (Mattos, \& Luz, 2012).

Chama a atenção que os sintomas da FM, com destaque para a dor difusa, não apresentam uma etiologia identificável por exame laboratorial. Por isso, a síndrome é diagnosticada mediante a verificação de critérios clínicos, que estabelecem a presença de pelo menos onze dos 18 pontos de dor sensíveis a dígito pressão de 4 kg/f; dor difusa por mais de três meses e ausência de evidência orgânica que explique os sintomas. Esses parâmetros foram definidos em 1990 pelo Colégio Americano de Reumatologia e é o mais citado na literatura (Helfenstein Junior et al., 2012; Mattos, \& Luz, 2012; Steffens et al., 2011), ainda que essa instituição já tenha formulado novos critérios no ano de 2010 (Braga, 2012).

Acerca de sua etiopatogenia, os estudos não indicam uma causa específica e há várias hipóteses para explicar a síndrome, tais como: a) disfunção do sistema fisiológico do estresse; b) distúrbio na modulação da dor no Sistema Nervoso Central, decorrente do déficit de serotonina e noradrenalina; c) produção de dor pela estimulação de neurônios não nociceptivos (ou seja, não especializados para estímulos dolorosos) na medula espinhal, em função do aumento de glutamina e substância P (Nunes, Nunes, Moraes, \& Uemura, 2012); d) fatores genéticos; e) desregulação imunológica por ataque de vírus (Berne, 2007) e, ainda, f) suposição de que a dor crônica, a ansiedade e a depressão, sintomas da fibromialgia, seriam a somatização do desconforto proveniente do trabalho (Mattos, \& Luz, 2012, p. 1459).

Dentre essas hipóteses, as três primeiras inscrevem-se nos estudos médicos e são entendidas como inter-relacionadas na gênese da dor crônica. Contudo, mesmo com essas possibilidades de explicação, o tra- 
tamento oferecido a pacientes crônicos apenas atenua os sintomas (Berne, 2007). Nessa situação, os estudos médicos têm buscado elucidar com mais precisão o processo fisiológico envolvido na FM, investigando formas mais efetivas de tratamento medicamentoso. Considerando a complexidade dessa síndrome, essas pesquisas defendem o trabalho multidisciplinar em saúde como o mais indicado, no qual a Psicologia poderia contribuir (Brandt et al., 2011; Cavalcante et al., 2006; Costa, et al., 2005; Freire et al., 2006; Helfenstein Junior et al., 2012; Ribeiro, \& Proietti, 2005; Saltareli, Pedrosa, Hortense, \& Sousa, 2008; Santos, Quintans Junior, Fraga, Macieira, \& Bonjardim, 2012).

A ciência psicológica é uma das áreas de conhecimento que tem investigado essa síndrome, apresentando, principalmente, um perfil psicológico do indivíduo diagnosticado com FM. Ele é descrito como alguém ansioso e deprimido (Jubran, \& Nicolau, 1999), perfeccionista (Jubran, \& Nicolau, 1999; Lima, \& Carvalho, 2008; Silva, \& Rocha Júnior, 2007), esquecido (Lima, \& Carvalho, 2008), sensível às mudanças e com capacidade diminuta para adaptar-se a elas (Jubran, \& Nicolau, 1999), exibindo, ainda, dificuldade de se relacionar com outras pessoas (Silva, \& Rocha Júnior, 2007).

Esses estudos aludem a traços de personalidade da pessoa diagnosticada com fibromialgia. O traço é uma forma "econômica" de descrever algumas características do repertório comportamental de uma pessoa (Skinner, 1953/2003a); um exemplo disso seria usar adjetivos, como perfeccionista, para descrever alguns padrões de comportamento de indivíduos fibromiálgicos. No entanto, ao fazer isso, as variáveis contextuais responsáveis pelo estabelecimento e manutenção desses padrões não são geralmente mencionadas. Além disso, os traços, que a princípio teriam um papel descritivo, podem assumir uma função explicativa, tornando-se causas daquilo que descrevem. Isso acontece quando o traço perfeccionista em questão é usado para explicar um dado padrão comportamental: a pessoa diagnosticada com fibromialgia comporta-se de determinada maneira porque é perfeccionista. Com essa suposta explicação, as variáveis contextuais são novamente desconsideradas. A identificação e a descrição dessas variáveis são importantes não apenas para ampliar a compreensão dos padrões de comportamento descritos por traços, mas também, e principalmente, porque são essas variáveis, e não os traços, que podem ser modificadas para promover mudança comportamental (Skinner, 1953/2003a).
Tendo isso em vista, a análise funcional, de base teórica analítico-comportamental, é uma forma de investigar os aspectos contextuais de um dado comportamento ou padrão comportamental. Mais especificamente, a análise funcional consiste na investigação das "contingências responsáveis por um comportamento ou por mudanças nesse comportamento" (Matos, 1999, p. 14). A contingência especifica a inter-relação entre: (A) ação de um indivíduo em uma determinada situação (S) e as consequências (C) produzidas pela ação, e como essas consequências, por sua vez, alteram a própria relação (Lopes, 2010). Analisar o comportamento com base na noção de contingência seria, então, descrevê-lo em termos dessas inter-relações. Pautando-se nesses conceitos, como entender a dor crônica à luz da Análise do Comportamento?

Umapossibilidade de interpretação analítico-comportamental da dor crônica se dá com base na teoria de eventos privados (Skinner, 1953/2003b). Dessa perspectiva, eventos privados são estímulos e respostas de acessibilidade pública restrita. Esses eventos são discriminados por meio da relação estabelecida entre um falante e uma comunidade verbal convencionada, que reforça o perceber e a descrição do falante acerca desses eventos. Para isso, a comunidade baseia-se em acompanhamentos públicos relacionados a estímulos e respostas privados (Skinner, 1945/1999, 1953/2003b). Por essa ótica, a dor poderia ser entendida como uma resposta encoberta controlada por estímulos dolorosos (exteroceptivos ou interoceptivos), cuja discriminação depende de contingências socioverbais (Skinner, 1945/1999, 1953/2003b).

Skinner $(1945 / 1999)$ menciona quatro procedimentos pelos quais a comunidade verbal modela e mantém um repertório comportamental descritivo de eventos privados. No primeiro procedimento, a comunidade verbal pauta-se em estímulos públicos relacionados ao estímulo privado que será ensinado a ser descrito. Assim, a comunidade verbal pode, por exemplo, reforçar a ação de uma criança de relatar dor, com base em um hematoma ou um corte (estímulo público). Nessa situação, quem reforça o comportamento de descrever "isso dói" está sob controle do estímulo visual na pele da criança (hematoma ou corte), mas não do "sentimento de dor". No segundo procedimento, a comunidade baseia-se em respostas colaterais públicas que regularmente acompanham uma condição privada. No caso da dor, respostas colaterais públicas podem ser um gemido, uma expressão facial, 
uma postura corporal específica. No terceiro procedimento, a comunidade verbal ensina o indivíduo a descrever o seu próprio comportamento. Isso não se refere ao que é percebido ("há um corte em minha pele"), mas ao próprio "sentir a dor" ("estou sentindo dor"). Já no quarto procedimento, a descrição das propriedades de um evento público (a inserção de uma agulha na pele) é utilizada, por analogia, para descrever um evento privado, com base em propriedades semelhantes entre esses eventos ("sinto como se uma agulha estivesse espetada em meu braço").

Se, de acordo com a teoria de eventos privados, a gênese do repertório discriminativo de um evento privado (como a dor, por exemplo) está relacionada ao comportamento verbal ensinado e convencionado em uma cultura, a dor seria apenas uma resposta encoberta controlada por estímulos culturalmente considerados dolorosos. Mas se a expressão facial de desconforto, o chorar e outras ações fazem parte da aprendizagem de relatar dor, esses acompanhamentos públicos não seriam, também, parte do que é denominado dor, uma vez que participam das mesmas contingências de reforçamento?

Nessa direção, Rachlin (2010) discute a característica de privacidade dos fenômenos comportamentais, assinalando que os eventos privados são parte de um conjunto de ações desempenhadas "publicamente”. A dor, nesses termos, é um rótulo que resume tanto aquilo que o organismo sente, como diferentes ações emitidas em determinadas situações, que produzem consequências semelhantes. Uma afirmação do tipo "Maria sente dor" resume Maria mancar, gemer, isolar-se, "fazer cara feia", ficar quieta no seu canto, chorar, gritar e assim por diante. Maria não faz essas coisas e sente dor (como se fossem dissociados entre si) ou porque a sente (como se as ações fossem expressões de uma fisiologia da dor). De outro modo, essas ações de Maria são a própria dor e, consequentemente, elas fazem parte de uma classe mais ampla de ações (Rachlin, 2010), estabelecidas e mantidas por contingências específicas.

Comparativamente, algumas explicações acerca da dor interpretam o choro de um bebê como "uma mensagem, uma representação, uma indicação, ou um sintoma de dor. Para o behaviorista [molar], o choro (mais os chutes, a expressão facial, e outras atividades explícitas) é a própria dor" (Rachlin, 2010, p. 439). Esse entendimento tem como pressuposto a superação da dicotomia entre interno (sentir) e externo (fazer). O caráter dicotômico desses domínios (interno/externo) atribui naturezas diferentes aos fenômenos humanos: há os inobserváveis (percepção da dor) e os observáveis (fisiologia da dor); os profundos (sentimentos) e os superficiais (ações); os determinantes (personalidade) e os que são mera expressão (comportamento). Em contrapartida, uma perspectiva molar de análise considera que o sentir e o fazer são fenômenos comportamentais, produzidos pelas mesmas contingências: "o sentir é tanto produto da variação e da seleção quanto o fazer. O sentir [sensingl é uma parte do fazer" (Skinner, 1990, p. 1207). Por isso, o procedimento mais coerente com uma ciência empírica do comportamento é a operacionalização, em termos da "identificação das contingências de reforçamento que descrevem as relações de controle de estímulos envolvidas" no objeto de estudo em questão (Lopes Júnior, 1997, p. 172).

Com base nesses pressupostos, a Análise do Comportamento entende que estudos sobre a FM, voltados para a descrição de sintomas, fisiologia ou perfis psicológicos são uma das etapas na pesquisa sobre esta síndrome. A outra etapa envolve a investigação das contingências que modelam e mantêm os comportamentos de dor, já que a modificação comportamental depende da compreensão das variáveis em vigor. Por esse motivo, a discussão psicológica sobre fibromialgia pode ser complementada com a investigação das variáveis relacionadas à construção do perfil psicológico de indivíduos diagnosticados com esta síndrome. Os estudos médicos também podem ser enriquecidos com uma explicação que ultrapasse a descrição de sintomas e mecanismos fisiológicos, considerando as variáveis contextuais da dor crônica, já que se trata do principal sintoma da fibromialgia.

Tendo isso em vista, esta pesquisa objetivou operacionalizar em termos de contingências uma definição de dor crônica no contexto da FM. Para tanto, esse fenômeno foi investigado de uma perspectiva molar, considerando a dor para além de seu funcionamento fisiológico. Assim, por meio de uma análise funcional, foram descritas possíveis contingências originárias e mantenedoras dos comportamentos de dor de indivíduos diagnosticados com fibromialgia.

\section{Método}

Nestapesquisa, denatureza empírico-exploratória, participaram oito mulheres diagnosticadas com FM que frequentavam regularmente o ambulatório de reu- 
matologia de um hospital universitário no estado do Paraná. As participantes apresentaram média etária de 52,5 anos (30-67 anos) e foram diagnosticadas com FM há pelo menos 1,5 anos. Além disso, entre as entrevistadas, uma era educadora infantil (que será referenciada por P1 neste artigo), três delas costureiras (P2, P3 e P4) e quatro donas de casa (P5, P6, P7 e P8). Essas participantes foram contatadas e selecionadas ao acaso e no momento de suas reconsultas ao ambulatório. A dinâmica de recrutamento das participantes foi assim definida por conta das normas do local da pesquisa, que não permitia o acesso a dados pessoais dos pacientes, como telefone. Dessa forma, uma das pesquisadoras frequentou o hospital em horários e dias diferentes da semana, aguardando que algum paciente com fibromialgia aparecesse para uma reconsulta. Quando isso ocorria, o médico e os residentes responsáveis pelo atendimento encaminhavam o atendido para a pesquisadora. Todos esses profissionais estavam cientes dos critérios de inclusão do paciente na pesquisa, quais sejam, o diagnóstico de FM e idade igual ou superior a 18 anos.

Para obtenção das informações foi utilizada uma entrevista semiestruturada. Esse instrumento envolveu a organização de um roteiro (Gerhardt, Ramos, Riquinho, \& Santos, 2009), com vistas a identificar as contingências relacionadas aos comportamentos de dor na fibromialgia. As perguntas levantaram informações a respeito dos sintomas mais frequentes; do histórico da FM; do diagnóstico e tratamento; dos contextos em que a dor e o quadro sintomático apareciam ou eram mais intensos; das ações das participantes nessas situações e suas consequências. Indagou-se também sobre como a fibromialgia interferia nas relações interpessoais, conjugais, no contexto de trabalho e lazer; além de como a participante se definia e como os outros a caracterizavam.

A utilização dessa modalidade de entrevista flexibilizou a condução das perguntas (Gerhardt et al., 2009), permitindo a solicitação de esclarecimentos, conforme a necessidade de detalhar algum assunto relatado pelas entrevistadas. Por exemplo, quando alguma participante relacionava o aumento da dor com "situações em que estava nervosa", perguntou-se sobre as ocasiões específicas em que isso acontecia, o que ela fazia nessas circunstâncias, como as pessoas a tratavam, o que se sucedia depois e quando a dor melhorava. Esses relatos foram gravados, mediante o consentimento das participantes, transcritos na ínte- gra e analisados qualitativamente com base na noção de tríplice contingência e de outros conceitos da teoria analítico-comportamental. Para tanto, a sistematização e interpretação dos dados envolveu estas etapas:

- Uma análise preliminar do material, na qual cada transcrição foi sistematizada, especificando a frequência da dor e demais sintomas descritos; contextos em que ocorriam; início, desenvolvimento, e diagnóstico da síndrome; padrão comportamental das participantes e suas histórias de vida. Posteriormente, os relatos foram comparados, buscando similaridades e diferenças.

- Reorganização das informações, conforme o conceito de contingência, especificando: a) as ações envolvidas na classe comportamental de dor, b) as consequências produzidas por essas ações no meio e c) o contexto no qual a classe comportamental ocorria.

- Análise geral e comparativa das análises funcionais de cada caso, especificando contingências originárias e mantenedoras da classe comportamental de dor. Essa interpretação em momentos distintos é justificada pela natureza processual e mutável do comportamento (Lopes, 2010), pois as variáveis relacionadas à gênese de um comportamento não participam necessariamente de sua manutenção.

Ressalta-se que este estudo seguiu os padrões éticos estabelecidos para pesquisa com seres humanos, sendo registrado na Plataforma Brasil (CAAE: 27051114.7.0000.0104) e aceito pelo Comitê Permanente de Ética em Pesquisa com Seres Humanos (parecer no 548.245 de 17/02/2014).

\section{Resultados/Discussão}

A análise do registro do comportamento verbal das entrevistadas conduziu, neste estudo, à caracterização das participantes como mulheres que sempre foram "ativas", "caprichosas", "responsáveis", "engajadas" em seus trabalhos, contribuindo, inclusive, para o sustento financeiro da família. Trata-se de mulheres que sempre tiveram o domínio das situações, monitorando onde os filhos estavam, decidindo sobre os assuntos familiares, tomando a iniciativa na realização de tarefas e exigindo que os afazeres fossem feitos do modo como elas julgavam correto. Com esse padrão de comportamento, produziram, ao longo da vida, bons resultados no contexto de trabalho, mantendo a ordem 
da dinâmica familiar e a organização do lar, como neste relato de $\mathrm{P} 7$, sobre os serviços domésticos:

Sempre fui assim uma pessoa que parece que assim "fuu" "fuuu". Eu farejo pó entendeu? Então, eu tenho que passar o pano na minha casa, todos os dias. Toda a semana eu tô lá com rodo. Quer dizer: estava. Estava com um pedaço de pano tirando as teias e, em seguida, um rodinho de espuma esfregando as paredes da minha casa, passando pano e enxugando para não umedecer.

À semelhança de $\mathrm{P} 7$, as demais participantes deste estudo, principalmente antes do diagnóstico de fibromialgia, envolviam-se em múltiplas tarefas durante o dia, apresentando-se, ainda, dispostas a ajudar as pessoas que eventualmente recorriam a elas. Essas características identitárias foram descritas pelas entrevistadas de um modo nostálgico, pois foi frequente em seus discursos o quanto elas almejam restituir o que eram e o que podiam fazer. Sobre isso, P7 descreve: "eu era uma pessoa sadia. Eu trabalhava fora, e quando eu chegava na minha casa eu fazia todo o serviço. Sempre fiz isso. Se me chamasse para fazer qualquer coisa, eu ia, fazia". Acrescentando, ela afirma: "tudo o que eu queria era um tratamento. Eu quero viver sem dor, ou pelo menos um remédio que tire a dor". Em geral, as participantes não aceitam suas restrições físicas e descrevem a incapacidade de realizar as tarefas com perfeição (por exemplo: não ter firmeza para cortar um legume ou para torcer uma roupa) como episódios acompanhados por "tristeza", "desânimo", "revolta" ou "desgosto".

As descrições das entrevistadas acerca de si e de como agem nos contextos em que estão inseridas, principalmente quando uma tarefa precisa ser cumprida, sugerem que elas apresentam um padrão comportamental perfeccionista. Outras pesquisas psicológicas também fizeram essa consideração, indicando que indivíduos diagnosticados com FM apresentaram um perfil perfeccionista (Jubran, \& Nicolau, 1999; Lima, \& Carvalho, 2008; Saltareli et al., 2008; Silva, \& Rocha Júnior, 2007).

Sob uma ótica analítico-comportamental, esse padrão envolve um conjunto de sentimentos e ações, tais como o sentimento de baixa autoestima, inabilidade para o autorreconhecimento, autocrítica, intolerância ao erro, sentimento de extrema responsabilidade e comportamento governado por regras e autorregras. A sua gênese, por sua vez, relaciona-se a contingências aversivas geradoras tanto do sentimento de baixa autoestima, quanto do sentimento de extrema responsabilidade (Guazi, \& Laurenti, 2015).

De acordo com Skinner (1989/1995), o sentimento de autoestima é produzido quando um comportamento é reforçado positivamente "e são geradas condições corporais passíveis de ser observadas e valorizadas pela pessoa cujo eu foi observado e valorizado" (p. 47). Quando uma pessoa tem seu "eu" valorizado pelos outros e percebe isso, há condições para que ela também se valorize, construindo autoestima e autorreconhecimento (Skinner, 1989/1995). Guilhardi (2002) amplia a explicação sobre esse sentimento, indicando que ele é instalado mediante reforçamento positivo social direcionado à pessoa e não a uma ação específica (Guilhardi, 2002). Isso significa que o feedback social positivo confere um senso de valor à pessoa, assim como se confere a um poeta, por sua sensibilidade ao escrever versos, mesmo que se conheçam as influências artísticas que contribuíram para a beleza do poema que construiu. Caso tais influências sejam consideradas as responsáveis pela qualidade do poema, isso invalidaria "qualquer reconhecimento que o poeta venha a receber dos outros e destrói seu o senso pessoal de valor" (Skinner, 1989/1995, p. 47).

Examinando as contingências que instalam o sentimento de autoestima, nota-se que, no caso de indivíduos com um padrão comportamental perfeccionista, o reconhecimento social é direcionado à ação da pessoa e não propriamente a ela. Em contraste, quando essa pessoa erra, a punição não é direcionada à ação considerada "indesejável" pelo punidor, mas à pessoa que a emitiu. Esse contexto não constrói o sentimento de autoestima, e sim um padrão comportamental em que fazer as tarefas com esmero é mantido por evitar erros, pois só assim é que o perfeccionista é reconhecido (Guazi, \& Laurenti, 2015).

As participantes deste estudo descreveram situações semelhantes em suas histórias de vida, indicando que quando elas receberam algum elogio, ele foi direcionado ao que elas "faziam" e não a suas pessoas, como neste relato de P4: "meus filhos às vezes me elogiam, falam que me admiram por eu fazer tudo assim do jeito que eu faço". Nesse excerto, o reconhecimento dos filhos é para a ação de P4 em realizar as tarefas com dedicação, não constituindo uma aprovação social direcionada à pessoa. Por outro lado, se o indivíduo erra ou não realiza uma atividade, na des- 
crição do agente punidor, a punição é dirigida à pessoa e não a uma ação específica, como na fala de P7, descrevendo o que as pessoas comentam sobre ela: "essa aí tinha uma energia, mas agora não é mulher para nada". Com isso, identifica-se, no relato das participantes, sentimentos de baixa autoestima apresentados sob forma de autocrítica: acham que tudo o que fazem sempre pode ser melhorado, reconhecendo poucas vezes aquilo que fazem ou fizeram. Isso pode ser ilustrado nestas falas: "eu me cobro assim, eu me sinto assim que eu tinha que ser uma pessoa mais inteligente, eu acho" (P6); "eu me cobro. O que eu faço, eu queria fazer melhor, fazer diferente" (P5); "tento me cobrar o máximo que eu posso" (P2).

Ratificando essa análise sobre o sentimento de baixa autoestima, os relatos sobre as histórias da infância e da adolescência trouxeram elementos que sugerem um arranjo de contingências aversivas, baseado na demanda pela realização de tarefas benfeitas e contingências de punição, como no relato de P5: "minha mãe exigia da gente o impossível. Quando a gente não conseguia fazer o que ela queria, ela batia na gente, era de cinta, era de vara. Ou faz ou faz, não tinha essa de meio termo". Essas contingências aversivas contribuíram para a instalação de um padrão comportamental perfeccionista caracterizado por baixa autoestima, visto que esse, reforçado negativamente, teve a função de evitar críticas sociais e depreciação da pessoa. À semelhança dessa análise, outras pesquisas indicam um predomínio de contingências aversivas na história de vida de indivíduos diagnosticados com FM (Queiroz, 2009; Reis, \& Rabelo, 2010; Silva, Rocha, \&Vandenberghe, 2010).

Tomando por base o itinerário percorrido até então, cabe ressaltar que a análise do padrão perfeccionista não se esgota na operacionalização do sentimento de autoestima. Como já indicado, as contingências que geram o sentimento de responsabilidade também estão envolvidas na construção de um padrão comportamental perfeccionista. Nesta pesquisa, todas as participantes relataram que precocemente tiveram muitas responsabilidades; uma exigência que foi se mantendo no curso de suas novas relações e foi se constituindo como um padrão de comportamento apresentado em diversos contextos (por exemplo, no trabalho, no pagamento de contas, nos serviços domésticos):

Quando perdi meu pai, eu tinha 12 anos, aí minha mãe ficava cobrando muito, tudo ela cobrava da gente, então foi tendo uma responsabilidade. Eu me tornei adulta com 13 anos de idade. 12 anos eu tive que parar de estudar para trabalhar (P4). [relatando o que ouvia de sua mãe] Eu tô saindo trabalhar. Vigia seu irmão e não fica na rua. Você vê o que você faz, porque eu vou cobrar de você. Quando eu chegar do serviço, se o teu irmão ficou na rua, se o teu irmão roubou, a responsabilidade é sua, eu vou cobrar de você, porque você que é mais velha (P1).

O sentimento de responsabilidade é construído por contingências coercitivas de cunho social (Skinner 1989/1995). Assim, comportamentos (por exemplo, cuidar do irmão mais novo) que evitam estímulos aversivos (por exemplo, castigo físico) são selecionados, emergindo, simultaneamente, o sentimento de responsabilidade sob controle dessa estimulação (Guilhardi, 2002). Contudo, o predomínio de contingências coercitivas na instalação desse sentimento pode influenciar negativamente o indivíduo em suas relações sociais. Indivíduos extremamente responsáveis preocupam-se com tudo e, em geral, não se interessam por lazer e férias (Guilhardi, 2002). Em última instância, isso pode restringir as possibilidades de reforçamento positivo para outros comportamentos em contextos que não imponham ao indivíduo altas exigências de desempenho (Guilhardi, 2002).

Na discussão do perfeccionismo, Guazi e Laurenti (2012) indicam que as contingências relacionadas ao sentimento de responsabilidade estiveram presentes no histórico de vida de indivíduos perfeccionistas. Nessas circunstâncias, essas pessoas estiveram expostas a demandas sociais por responsabilidade extrema em um período precoce de suas vidas, "seja pela natureza do compromisso que tinham que assumir, seja pelo grau de exigência envolvido na execução tarefa" (p. 4). As autoras acrescentam que a gênese desse padrão responsável se relaciona à falta de "uma audiência significativa que intercedesse frente. . à coerção" (Guazi, \& Laurenti, 2012, p. 4). Neste estudo, os relatos das entrevistadas sobre infância e adolescência corroboram com essas considerações, como neste excerto:

Meus pais eram muito rígidos. Eu fui uma pessoa que eu não saía de casa. Eu fiquei na escola até os 12 anos e me tiro[u] da escola para trabalhar na roça. "Aonde que já se viu uma moça tá desse tamanho estudar?". Era dessa maneira que meus pais falava[m] (P6). 
Além da baixa autoestima e extrema responsabilidade, as participantes deste estudo também apresentaram comportamentos governados por regras e autorregras. Tais comportamentos, originados por contingências aversivas, têm alta probabilidade de ocorrer quando evitam ou adiam consequências negativas. Assim, quando o indivíduo considerado perfeccionista está sob o controle de regras, aumenta-se a probabilidade de ele não errar, uma vez que uma regra é construída por experiências acumuladas, funcionando como uma instrução para o acerto, sem necessariamente ter que repetir todo o processo que deu origem aquela regra (Guazi, \& Laurenti, 2015).

As autorregras também participam desse contexto; nesses casos, a regra é formulada pela própria pessoa. P4, por exemplo, depois de contratar uma empregada doméstica que não limpava a casa assim como esperado, chegou a conclusão de que somente ela é que tem competência para realizar esse serviço: "eu que tenho que fazer, pois quando eu faço sai bem-feito". As participantes apresentam a exigência de que os outros sigam à risca suas autorregras e, por isso, acabam sendo vistas pelos pares como pessoas "controladoras", que precisam ter o domínio de tudo o que acontece. Silva et al. (2010) fizeram análise semelhante, indicando que suas pacientes "acumulavam rotinas exaustivas e centralizavam responsabilidades" (p. 340).

No entanto, a forma de agir das participantes não envolve somente contingências aversivas. O exemplo de autorregra de P4 descreve também o sentimento de autoconfiança, característico das entrevistadas, principalmente quando falam do passado. Esse sentimento é produzido por reforçamento positivo e negativo em relação à execução da própria tarefa. Uma pessoa segura e confiante é a que consegue ser bem-sucedida na produção de reforçadores positivos e na remoção de eventos aversivos na situação em que está inserida (Guilhardi, 2002). As participantes relataram essa capacidade e o quanto suas ações alcançavam a exigência de qualidade que estabeleciam como objetivo, obtendo, por exemplo, uma casa limpa e organizada, o cumprimento de meta de peças de roupas costuradas, e assim por diante. Dessa forma, ao tomarem para si a responsabilidade de realizar as atividades com precisão, comandando como os afazeres devem ser feitos ou as regras seguidas, elas agiram sobre o ambiente. Como consequência, evitaram a realização malfeita de tarefas e produziram reforçadores positivos advindos da execução da própria atividade, favorecendo o sentimento de autoconfiança.
Com base nessa discussão, delineia-se uma análise do padrão perfeccionista, que se destacou nos relatos das entrevistadas nesta pesquisa. Esse padrão foi construído com a função de remover estímulos aversivos, como críticas sociais do punidor direcionada à pessoa e término malfeito das tarefas. Com isso, sua origem está relacionada às contingências que instalaram os sentimentos de baixa autoestima e de extrema responsabilidade. Ao mesmo tempo, o padrão emitido foi reforçado positivamente quando as mulheres, ao agirem no ambiente, produziram os resultados esperados na própria execução de seus afazeres, instalando-se, desse modo, o sentimento de autoconfiança.

Considerando essas análises, qual a relação entre o padrão comportamental perfeccionista e a dor crônica no contexto da fibromialgia? Sobre isso, dois elementos se configuraram como preponderantes no surgimento e desenvolvimento da dor crônica: mudanças contextuais e limitações físicas. O primeiro foi descrito pelas participantes como "desencadeante" da FM. De acordo com o relato de P4, as crises começaram depois que descobriu um nódulo no seio; para P7 a FM apareceu após uma queda que ocasionou lesão na coluna; para P2 a FM desenvolveu-se alguns dias depois de um diagnóstico de hérnia de disco; P6 assinala o abandono do marido, a filha que fugiu com o namorado e a mudança da zona rural para urbana como precedentes à síndrome; P5, por sua vez, afirma que a FM veio com o lúpus, a morte do pai e que as dores se intensificaram quando se separou do cônjuge; e, por fim, P3 assinalou o aparecimento dos sintomas e o consequente diagnóstico de FM após um procedimento cirúrgico. Sobre esse ponto, outras pesquisas indicaram eventos estressores como antecedentes ao diagnóstico de FM, tais como morte de parentes (Silva, \& Rocha Júnior, 2007), dificuldades conjugais e perda do emprego (Costa et al., 2005).

Os eventos mencionados neste estudo, e também os da literatura, remontam à dificuldade do indivíduo diagnosticado com FM adaptar-se às mudanças (Jubran, \& Nicolau, 1999). Para uma pessoa considerada perfeccionista, como é o caso das participantes desta pesquisa, a mudança abrupta configura um contexto desfavorável, pois não permite o domínio das situações (por exemplo: saber onde o filho está; impedir que o marido vá embora de casa; realizar as tarefas com perfeição, por conta de uma hérnia de disco ou artrite/artrose), produzindo eventos aversivos. Com essas mudanças de contexto, as ações per- 
feccionistas de outrora ou não têm ocasião para ser emitidas, ou quando o são, não mais produzem consequências reforçadoras (positivas ou negativas). As consequências aversivas que surgem envolvem tarefas domésticas malfeitas; desempenho insatisfatório no emprego (não conseguir atingir a meta de roupas costuradas, por exemplo) e crítica social, principalmente no contexto de trabalho.

Tomando por base essa análise, o diagnóstico de FM anunciado como uma síndrome "incurável" constitui-se como uma situação de incontrolabilidade e, por isso, é um novo desafio ao padrão perfeccionista. As mulheres relatam o momento de recebimento da devolutiva pelo médico como desagradável: "foi meio triste receber esse diagnóstico, você não tem remédio para isso, não tem cura, nada que prova que você tá com isso, fiquei meio abalada" (P4); "eu não acredito que é essa doença. Porque eu não sei nada dela" (P7); "eu procuro pensar: eu não tenho esse problema e não é o fim do mundo" (P2); "eu só me admirei, só. Eu fiquei admirada: poxa tenho lúpus, mais uma coisa ainda" (P5); "ele [o médico] logo de cara já me matou". Esses relatos ilustram o quanto o diagnóstico de FM é uma situação inesperada, considerando que a síndrome é anunciada como incurável e, por isso, figura como uma mudança que as participantes não podem controlar.

Sumariamente, pode-se dizer que a FM e a dor crônica como a característica mais relevante dessa síndrome emergem em um contexto de incompatibilidade entre situações de difícil controle e o padrão comportamental perfeccionista. Além disso, essa incompatibilidade gera uma série de respondentes que acabam se sobrepondo aos operantes (Keller, \& Schoenfeld, 1970). Os aspectos respondentes presentes na FM são a mobilização biológica de estresse (alteração dos batimentos cardíacos, aumento da pressão sanguínea etc.) e resposta nociceptiva (de dor). Entre as participantes, seis relataram a ocorrência desses respondentes, com subsequente aumento da dor, em contextos em que não detinham o controle das situações, como neste relato de P6: "a gente tá vendo que não é daquele jeito, vai orientar e recebe uma má resposta e aquilo o sangue parece que vai lá. Aí vem o nervosismo e pode esperar a doiarada".

Somado a isso, o desgaste físico foi um segundo elemento de destaque no desenvolvimento da FM. Provavelmente, essa condição corporal deriva do uso intensivo do corpo ao longo da vida na realização de tarefas e em duplas jornadas de trabalho (no trabalho e afazeres domésticos). As entrevistadas desta pesquisa estiveram mais sob controle das consequências produzidas por suas ações do que das condições corporais relacionadas ao uso vigoroso do corpo. Assim, o padrão perfeccionista contribuiu para que as participantes atingissem um elevado estado de estresse, indo até a exaustão. Quando se alcança esse limite, os sinais de desgaste físico tornam-se mais conspícuos, sendo mais provável que as participantes fiquem sob controle deles. Essa análise assenta-se nos relatos das entrevistadas que assinalaram tanto seus esforços físicos precoces e suas condições físicas atuais, principalmente em relação aos serviços domésticos, caracterizadas como "volto bagaçada”, "eu não aguento", "eu não consigo mais", "tive que mudar minha rotina", "parece perna de pano", "tenho que sentar". Acerca disso não foram encontrados estudos nacionais que correlacionassem um histórico de desgaste corporal com o diagnóstico de FM. No entanto, pesquisas atestam que os indivíduos diagnosticados apresentam força muscular aquém da esperada para sua idade (Angel, Campos, Meza, Fernadez, \& Heredia, 2012; Cardoso, Curtolo, Natour, \& Lombardi Júnior, 2011).

Ressalta-se que, por mais que as entrevistadas tenham relatado essas limitações corporais e os impactos negativos delas nas suas rotinas de trabalho, verifica-se uma persistência na realização de tarefas cotidianas, assim como indicado na literatura (Saltareli et al., 2008). As participantes continuam a emitir o padrão comportamental perfeccionista, embora as condições contextuais (como desgaste físico da participante) não favoreçam a produção de reforçadores, sejam eles positivos (uma tarefa bem-feita) ou negativos (evitar o mau desempenho da atividade). Essa persistência pode ser ilustrada nas seguintes descrições: "eu tenho que lutar mais para poder fazer" (P4); "eu começo. E quando eu pego, começo, eu termino, não importa se tiver dor" (P5); "enquanto eu vou aguentando, eu vô fazendo alguma coisa" (P8). Ao mesmo tempo, as entrevistadas também relataram terem deixado de executar tarefas: "eu não saía de casa se eu deixasse um copo sujo em cima da pia. Hoje não, hoje minha casa fica 15, 20 dias sem limpar. Então, às vezes eu fico triste por isso" (P4); "olha tem dia que eu fico tão desacorçoada que eu não faço nada, que eu fico muito deprimida" (P5); "o que mais incomoda é o desânimo. Incomoda muito a gente, porque você vê as coisas precisando de fazer e a coragem não dá. E aquilo vai irritando a gente" (P6).

Considerando esses dados, como entender, por um lado, o engajamento na realização de tarefas e, 
por outro, a renúncia em fazê-las (como deixar a casa durante dias sem limpar)? Há momentos em que as participantes dizem se sentir melhor fisicamente e executam diversas atividades, tendo como consequência o término da tarefa, como indica P5: "o dia que eu tô bem não tem moleza para trabalhar". Essa persistência acaba gerando incompreensão por parte das pessoas que convivem com as entrevistadas, já que elas reclamam de suas dores, mas continuam executando suas tarefas com esmero. Todavia, há ocasiões em que esse desempenho não é atingido e as entrevistadas param de realizar a atividade: "eu costumava pentear os cabelos da minha filha. Eu não consigo mais. Eu pego a escova, né, mas eu não consigo dar a volta na escova, aí eu paro" (P7).

Além disso, essas mulheres não estabelecem limites para o próprio corpo e executam a atividade até o máximo que conseguem, sugerindo um pareamento entre exaustão corporal e tarefa bem desempenhada: "enquanto eu vou aguentando eu vô fazendo alguma coisa. A hora que eu não aguento, eu deito" (P8); "no serviço de costureira eu vou sentindo a dor, mas ali eu fico sentada. Aí a hora que eu levanto, eu levanto cambotiando, eu vou fazer uma comida, ou senão, vou direto para minha cama" (P4). Desse modo, no começo da realização da atividade, elas estão sob controle de consequências reforçadoras (como evitar a tarefa malfeita, por exemplo). Mas a permanência na atividade vai tornando-se insustentável fisicamente, ao ponto de suspenderem a ação. Com isso, tem-se um círculo vicioso: (1) fazer a tarefa, sem perceber os limites do corpo, (2) exaustão corporal e realização malfeita da tarefa, (3) deixar de fazer a tarefa. Nessa direção, quando as mulheres relatam passar por momentos de crise (períodos de dor intensa), identifica-se uma diminuição na frequência de ocorrência de atividades que sinalizam exaustão corporal e desempenho impreciso de tarefas.

Em última instância, ocorre uma substituição gradual do "fazer com perfeição" para o "evitar realizar as tarefas", "evitar sair com os amigos" ou "ficar quieta em um canto". Semelhantemente, Silva et al. (2010) indicaram em sua pesquisa que pacientes diagnosticadas com fibromialgia evitam contato social e procuram isolar-se. Essas ações podem ser classificadas por sua função como fuga e esquiva, relacionando-se ao padrão comportamental perfeccionista, pois apresentam a mesma função que esse padrão tem: evitar erros. Tal aspecto é ilustrado por estes excertos: "muitas vezes já perco o temperamento, já fico ali na minha solidão, já fico ali no meu canto, já não quero conversa" (P7); "eu me fecho, às vezes eu não quero nem falar com ninguém, às vezes eu penso até que é uma depressão" (P6); "eu fico deitada no meu cantinho" (P5); "eu deito, fico quieta e choro muito" (P1).

$\mathrm{Na}$ medida em que as participantes deixam de executar tarefas, elas evitam críticas sociais e a autocrítica sobre aquilo que elas julgam poder ter feito melhor. Em outras palavras, essas ações (que adiam ou eliminam consequências aversivas) produzem mudanças ambientais, como evitar a tarefa malfeita, visto que elas nem são iniciadas. No entanto, quando as entrevistadas deixam de realizar as tarefas, ocorre uma diminuição das ocasiões para reforçamento positivo advindo da própria execução da atividade. Isso, por sua vez, gera um sentimento de falta de confiança na capacidade de apresentar um bom desempenho na realização de uma atividade. Essa contingência, caracterizada pelo padrão comportamental de fuga e esquiva e, com isso, déficit de reforçadores positivos, pode estar na gênese e manutenção do "desânimo", relatado por quatro $(50 \%)$ das participantes como falta de vontade para fazer as coisas: "às vezes eu não tenho vontade de fazer nada. As atividades normais de uma casa você não consegue fazer" (P4); "com essas dores eu não tenho vontade de me arrumar, eu não tenho vontade de sair. Às vezes, eu fico sentada, fico, fico, fico" (P7); "o que mais incomoda é o desânimo"(P6); "aquele dia eu não tenho vontade de comer, beber, tomar banho, nem falar, nem nada" (P1). Esses dados vão ao encontro das informações encontradas na literatura sobre o assunto, que destacam a associação de FM com depressão (Martinez, Panossian, \& Gaviolli, 2006; Mattos, \& Luz, 2012) em $39,2 \%$ a $50 \%$ de indivíduos diagnosticados com FM (Costa et al., 2005; Santos et al., 2012).

Ademais, o padrão comportamental de fuga e esquiva também tem sido emitido no contexto das relações interpessoais dessas mulheres. As participantes dizem evitar sair com amigos, família, de ir à casa de parentes e conversar com outras pessoas sobre a FM. Esses comportamentos de esquiva são mantidos por adiar a apresentação de eventos aversivos, tais como: (i) conversar com outras pessoas e dizer que no momento estão afastadas do trabalho e que em casa elas não têm feito todo o serviço; (ii) apresentar tarefas malfeitas aos outros, ou falar sobre isso; e, ainda, (iii) ouvir a dúvida dos pares quanto à condição de saúde da entrevistada ser verdadeira ou um fingimento. Assim, situações sociais passam a sinalizar consequências aversivas. 


\section{Considerações finais}

Este estudo objetivou compreender a dor crônica no contexto da FM de uma ótica analítico-comportamental molar. Dessa perspectiva, a dor crônica envolve um conjunto amplo de ações, públicas ou não, que requerem uma análise contextual (isto é, em termos de contingências) - o que ultrapassa a noção de que a dor crônica se limita uma resposta fisiológica do organismo de acessibilidade pública restrita.

Isso possibilitou a operacionalização da dor crônica em termos de contingências originárias e mantenedoras, destacando-se o caráter mutável e processual do comportamento, pois as variáveis envolvidas na gênese da dor crônica não são necessariamente as mesmas que a mantêm. Considerando as contingências originárias, as entrevistadas desenvolveram um padrão comportamental perfeccionista, derivado, sobretudo, de contingências aversivas, envolvendo punição direcionada à pessoa, quando realizavam mal uma tarefa. Assim, as participantes, ao longo da vida, utilizaram intensivamente seus corpos, atingindo o exímio desempenho de funções sociais, como mãe, dona de casa, esposa e funcionária. Essas ações, por sua vez, estiveram acompanhadas por sentimentos de baixa autoestima e de extrema responsabilidade, uma vez que a gênese de tais sentimentos está relacionada às mesmas contingências que construíram o padrão comportamental perfeccionista, característico dessas mulheres.

Ainda nesse âmbito, vale ressaltar que as entrevistadas concentravam e gerenciavam diversas atividades cotidianas: sabiam onde os filhos estavam, tomavam iniciativa das decisões e realizavam tarefas conforme suas regras, isto é, com perfeição. Esse desempenho evitou punições sociais, proporcionando, ao mesmo tempo, reforçadores positivos advindos da própria execução das tarefas, ao passo que essas mulheres alcançavam altas exigências de qualidade na realização de seus afazeres. Com isso, suas ações eram acompanhadas por sentimentos de autoconfiança.

Em contrapartida, algumas contingências mantenedoras podem ser caracterizadas como não passíveis de total controle, por conta da exaustão corporal das participantes e de mudanças contextuais. Por conseguinte, as participantes não conseguem manter o mesmo ritmo de antes no cumprimento das atividades, atingir a exigência de qualidade que estabeleceram para si mesmas e, tampouco, manter o controle das situações como outrora. Nesse contexto, comportamentos de fuga e esquiva são emitidos com uma função seme- lhante ao padrão perfeccionista: evitar a realização malfeita de tarefas e críticas sociais, considerando que, em algumas situações, as atividades sequer são iniciadas. Um dos resultados desse arranjo é o "desânimo", relacionado à a) esquiva de realização de tarefas, b) redução do contato interpessoal e, consequentemente, c) limitação das possibilidades de reforçamento positivo, no âmbito de execução da própria tarefa.

Com essa análise, a operacionalização da dor crônica na FM, em termos de suas contingências mantenedoras, sugere que essa classe comportamental envolve respostas eliciadas (alterações fisiológicas como a mobilização biológica de estresse e resposta nociceptiva) e comportamentos operantes (deixar de realizar as tarefas, deixar de sair de casa e com os amigos, isolar-se), tendo como antecedentes situações de incontrolabilidade e de limitação corporal, e como consequências: evitação de reprovação social, dúvida dos pares quanto à dor ser real ou fingimento da participante e realização malfeita de tarefas.

Essa análise contextual da dor crônica pode contribuir para o aperfeiçoamento teórico dos estudos sobre fibromialgia, complementando a literatura médica e psicológica sobre o assunto, uma vez que essas pesquisas definiram, predominantemente, a FM por meio da descrição dos aspectos da síndrome (os sintomas mais frequentes, fatores desencadeantes, perfil psicológico e a hipótese fisiológica de seu funcionamento). Adicionalmente, esta pesquisa pode complementar também outros estudos analítico-comportamentais nacionais sobre a FM (Martins, \& Vandenberghe, 2007; Queiroz, 2009; Reis, \& Rabelo, 2010) ao nortear-se por uma perspectiva ampliada de dor crônica como classe comportamental, não restringindo a dor a eventos privados.

Já na esfera prática, os resultados podem proporcionar amparo teórico para o delineamento de novas técnicas ou tratamentos psicoterápicos, focalizando, em especial: a) o sentimento de baixa autoestima; b) comportamentos "rígidos" frente à premência de mudanças; c) delineamento de autocontrole na realização de tarefas, evitando excessos corporais; d) fuga e esquiva que impedem possíveis processos de reforçamento positivo. As mudanças, relacionadas a esses alvos terapêuticos, começam com a aceitação do indivíduo de sua condição de saúde, entendendo que isso não implica em total incapacidade para realizar tarefas e manter uma vida social, mas uma correção de excessos e modulação de exigências. 
Ressalta-se que a utilidade dos resultados deste estudo não se limita ao campo de atuação do psicólogo. O médico, por exemplo, pode levar em consideração as características comportamentais dos indivíduos diagnosticados com fibromialgia, buscando construir uma relação médico-paciente que aumente as chances de os tratamentos (medicamentoso e alternativo) serem efetivos. O planejamento desse contato interpessoal pode levar em conta também o momento de comunicar o diagnóstico de FM. Dizer que fibromialgia "não tem cura" sinaliza para o(a) paciente mais uma situação de incontrolabilidade e, por isso, desfavorável ao se considerar uma pessoa de padrão comportamental perfeccionista. Por outro lado, a emissão do diagnóstico de FM pode ser conduzida de modo a ser uma ocasião favorável para modificações que propiciem a qualidade de vida da pessoa diagnosticada com a síndrome. Assim, a devolutiva pode deixar de dar destaque ao caráter incurável da FM, enfatizando as possibilidades de mantê-la sob controle e levar uma vida saudável e produtiva. Para tanto, a prestação de informações é uma ferramenta útil, pois ela pode ajudar o diagnosticado a perceber aspectos em sua rotina que precisam ser modificados, tais como modular os excessos no uso do corpo e os benefícios de realizar atividades prazerosas.

Com esses apontamentos, estudos futuros podem pesquisar métodos terapêuticos que envolvam a multidisciplinaridade no tratamento da fibromialgia, considerando que se trata de uma temática passível de diversas intersecções: Enfermagem, Educação Física, Medicina e Psicologia. Além disso, no campo psicológico, outras pesquisas podem contribuir, investigando: a) as formas mais efetivas de abordar o paciente em crise (logo que ele procura um serviço de saúde), de dar o diagnóstico de fibromialgia e de acompanhar o tratamento a longo prazo; b) as rela- ções familiares e como oferecer suporte aos pares que convivem com pessoas acometidas pela síndrome; e c) as diferenças e as similaridades da fibromialgia entre homens e mulheres.

Ademais, indica-se que conquanto este trabalho envolva suas peculiaridades e potencialidades nas interfaces entre a Psicologia, em especial a Análise do Comportamento, com as ciências da saúde, também podem ser apontadas limitações. Durante o processo de entrevista houve dificuldades em encontrar indivíduos diagnosticados apenas com FM, visto que essa síndrome aparece associada em $20 \%$ a $35 \%$ dos pacientes com desordens autoimunes, como lúpus eritematoso sistêmico e artrite reumatoide (Ribeiro, \& Proeitti, 2005). Neste trabalho, duas das participantes também foram diagnosticadas com lúpus e outras três com reumatismo, artrite ou artrose e, por isso, esses diagnósticos são variáveis não analisadas nestas discussões. Além disso, as contingências e os respectivos padrões comportamentais propostos como esboço analítico não foram levantados por meio de observação do comportamento das entrevistadas em diversos contextos ou no contato com seus pares. Esta interpretação foi baseada no registro do comportamento verbal das participantes (transcrições na íntegra das entrevistas) e no contexto de diálogo entre entrevistada e uma das pesquisadoras. Esse aspecto precisa ser levado em consideração, tendo em vista que a descrição de comportamentos ou situações foi feita da perspectiva das participantes. Sobre isso, considera-se que as entrevistadas estão inseridas em um contexto socioverbal que incentiva o indivíduo a relatar mais o que está sentindo, do que a discriminar propriamente as variáveis mantenedoras de seus comportamentos e sentimentos. No entanto, esses elementos não parecem comprometer os resultados da pesquisa, tampouco suas contribuições teórico-práticas no estudo da fibromialgia.

\section{Referências}

Angel, L. R. P., Campos, M. A. S., Meza, J. A. M., Fernadez, M. D., \& Heredia, J. M. (2012). Análise das capacidades físicas de mulheres com fibromialgia segundo o nível de gravidade da enfermidade. Revista Brasileira Medicina do Esporte, 18(5), 308-312. https://doi.org/10.1590/S1517-86922012000500005

Berne, K. (2007) Síndrome da fadiga crônica, fibromialgia e outras doenças invisíveis. Rio de Janeiro: Qualitymark.

Braga, B. P. (2012). Fibromialgia: o desafio do diagnóstico [Dissertação de mestrado]., Universidade da Beira Anterior, Covilhã, Portugal.

Brandt, R., Fonseca, A. B. P., Oliveira, L. G. A., Steffens, R. A. K, Viana, M. S., \& Andrade, A. (2011). Perfil de humor de mulheres com fibromialgia. Jornal Brasileiro de Psiquiatria, 60(3), 216-220. https://doi.org/10.1590/S0047-20852011000300011 
Braz, A. S., Paula, A. P., Diniz, M. F. F. M., \& Almeida, R. N. (2011). Uso da terapia não farmacológica, medicina alternativa e complementar na fibromialgia. Revista Brasileira de Reumatologia, 51(3), 269-282. https://doi.org/10.1590/S0482-50042011000300008

Cavalcante, A. B., Sauer, J. F., Chalot, S. D., Assumpção, A., Lage, L. V., Matsutani, L. A., \& Marques, A. P. (2006). Prevalência de fibromialgia: uma revisão de literatura. Revista Brasileira de Reumatologia, 46(1), 40-48. https://doi.org/10.1590/S0482-50042006000100009

Cardoso, F. S., Curtolo, M., Natour, J., \& Lombradi Júnior. (2011). Avaliação da qualidade de vida, força muscular e capacidade funcional em mulheres com fibromialgia. Revista Brasileira de Reumatologia, 51(4), 344-350. https://doi.org/10.1590/S0482-50042011000400006

Costa, S. R. M. R., Pedreira Neto, M. S., Tavares Neto, J., Kubiak, I., Dourado, M. S., Araújo, A. C et al. (2005). Características de pacientes com síndrome da fibromialgia atendidos em hospital de Salvador-BA, Brasil. Revista Brasileira de Reumatologia, 45(2), 64-70. https://doi.org/10.1590/S0482-50042005000200004

Freire, M., Teodoro, R. B., Oliveira, L. B., Cunha, S. F. C., Ferreira, B. P., \& Borges, M. F. (2006). Concomitância de fibromialgia em pacientes portadores de hipotireoidismo e de alterações tireoidianas em pacientes com fibromialgia. Revista Brasileira de Reumatologia, 46(1), 11-15. https://doi.org/10.1590/S0482-50042006000100004

Gerhardt, T. E., Ramos, I. C. A., Riquinho, D. L., \& Santos, D. L. (2009). Estrutura do projeto de pesquisa. In T. E. Gerhardt, \& D. T. Silveira (Orgs.), Métodos de pesquisa (pp. 65-89). Porto Alegre, RS: Editora da UFRGS.

Guazi, T. S., \& Laurenti, C. (2012). Perfeccionismo à luz da tríplice contingência: esboço de uma análise. Anais do II Seminário de Prática de Pesquisa em Psicologia da Universidade Estadual de Maringá (pp. 1-5). Maringá, PR.

Guazi, T., \& Laurenti, C. (2015). Subsídios da análise do comportamento para uma discussão do padrão perfeccionista na docência. Psicologia Revista, 24(2), 289-309. Recuperado de https://revistas.pucsp.br/index.php/psicorevista/article/view/27802

Guilhardi, H. J. (2002). Auto-estima, autoconfiança e responsabilidade. In M. Z. S. Brandão, F. C. S. Conte, \& S. A. B. Mezzaroba (Orgs.), Comportamento humano: tudo (ou quase tudo) que você precisa saber para viver melhor (pp. 63-98). Santo André: ESETec.

Helfenstein Júnior, M., Goldenfum, M. A., \& Siena, C. A. F. (2012). Fibromialgia: aspectos clínicos e ocupacionais. Revista da Associação Médica Brasileira, 58(3), 358-365. https://doi.org/10.1590/S0104-42302012000300018

Jubran, S. D. K., \& Nicolau, M. C. M. C. (1999). Contribuições da psicologia no tratamento de pacientes com fibromialgia. Psikhê, 4(1), 8-13.

Keller, F. S., \& Schoenfeld, W. N. (1970). Condicionamento operante. In F. S. Keller, \&W. N. Schoenfeld, Princípios de psicologia (pp. 52-81). São Paulo, SP: Herder.

Lima, C. P., \& Carvalho, C. V. (2008). Fibromialgia: uma abordagem psicológica. Aletheia, (28), 146-158. Recuperado de http://pepsic.bvsalud.org/scielo.php?script=sci_arttext\&pid=S1413-03942008000200012

Lopes, C. E. (2010). O comportamentalismo radical. In A. A. L. Ferreira (Ed.), A pluralidade do campo psicológico (pp. 91-108). Rio de Janeiro, RJ: UFRJ.

Lopes Júnior, J. (1997). Sobre a incidência do operacionismo na psicologia. In R. A. Banaco (Org.), Sobre comportamento e cognição (pp. 167-173). São Paulo, SP: Arbytes.

Martins, M. A., \&Vandenberghe, L. (2007). Intervenção psicológica em portadores de fibromialgia. Revista Dor, 8(4), 1103-1112.

Martinez, J. E., Panossian, C., \& Gavioli, F. (2006). Estudo comparativo das características clínicas e abordagem de pacientes com fibromialgia atendidos em serviço público de reumatologia e em consultório particular. Revista Brasileira de Reumatologia, São Paulo, 46(1), 32-36. https://doi.org/10.1590/S0482-50042006000100007

Matos, M. A. (1999). Análise funcional do comportamento. Revista Estudos de Psicologia, 16(3), 8-18. https://doi.org/10.1590/S0103-166X1999000300002

Mattos, R. S., \& Luz, M. T. (2012). Quando a perda de sentidos no mundo do trabalho implica dor e sofrimento: um estudo de caso sobre fibromialgia. Physis, 22(4), 1459-1484. https://doi.org/10.1590/S0103-73312012000400011

Nunes, S. O. V., Nunes, L. V. A., Moraes, J. B., \& Uemura, V. (2012). Transtorno depressivo e fibromialgia: associação em estresse de vida precoce. Relato de caso. Revista Dor, São Paulo, 13(3), 282-286. https://doi.org/10.1590/S1806-00132012000300015 
Queiroz, M. A. M. (2009). Seleção de alvos. In M. A. M. Queiroz, Psicoterapia comportamental e fibromialgia: alvos para intervenção psicológica (pp. 49-91). Santo André: ESETec.

Rachlin, H. (2010). Dor e comportamento. Temas em Psicologia, 18(2), 429-447. Recuperado de http:/ / pepsic.bvsalud.org/scielo.php?script=sci_arttext\&pid=S1413-389X2010000200017

Reis, M. D., \& Rabelo, L. Z. (2010). Fibromialgia e estresse: explorando relações. Temas em Psicologia, 18(2), 399-414. Recuperado de http://pepsic.bvsalud.org/scielo.php?script=sci_arttext\&pid=S1413-389X2010000200014

Ribeiro, L. S., \& Proeitti, F. A. (2005). Fibromialgia e estresse infeccioso: possíveis associações entre a síndrome de fibromialgia e infecções viróticas crônicas. Revista Brasileira de Reumatologia, 45(1), 20-29. https://dx.doi.org/10.1590/S0482-50042005000100005

Saltareli, S., Pedrosa, D. F. A., Hortense, P., \& Sousa, F. A. E. F. (2008). Avaliação de aspectos quantitativos e qualitativos da dor na fibromialgia. Revista Brasileira de Reumatologia, 48(3), 151-156. https://doi.org/10.1590/S0482-50042008000300004

Santos, E. B., Quintans Junior, L. G., Fraga, B. P., Macieira, J. C., \& Bonjardim, L. R. (2012). Avaliação dos sintomas de ansiedade e depressão em fibromiálgicos. Revista Escola de Enfermagem USP, 46(3), 590-596. https://doi.org/10.1590/S0080-62342012000300009

Silva, D. S., Rocha, P., \& Vandenberghe, L. (2010). Tratamento psicológico em grupo para dor crônica. Temas em Psicologia, 18(2), 335-343. Recuperado em de http://pepsic.bvsalud.org/scielo.php?script=sci_arttext\&pi$\mathrm{d}=\mathrm{S} 1413-389 \mathrm{X} 2010000200008$

Silva, S. N., \& Rocha Júnior, A. (2007). Características psicológicas presentes em mulheres portadoras de fibromialgia. Revista Educação, 2(1), 55-63. Recuperado de http://revistas.ung.br/index.php/educacao/article/view/54/85.

Skinner, B. F. (1990). Can psychology be a science of mind? American Psychologist, 45(11), 1206-1210. Recuperado de https://pdfs.semanticscholar.org/9252/422937bbe2b3ecb84f7ff4cd94f00db4bda9.pdf

Skinner, B. F. (2003b). Eventos privados em uma ciência natural. In Ciência e comportamento humano (J. C. Todorov, \& R. Azzi, trads., 1la. ed., pp. 281-309). São Paulo, SP: Martins Fontes. (Trabalho original publicado em 1953).

Skinner, B. F. (2003a). Função versus aspecto. In Ciência e comportamento humano (J. C. Todorov, \& R. Azzi, trads., 11a. ed., pp. 211-223). São Paulo, SP: Martins Fontes. (Trabalho original publicado em 1953).

Skinner, B. F. (1995). Questões teóricas. In B. F. Skinner, Questões recentes na análise comportamental (A. L. Neri, trad., 2a ed., pp. 13-71). Campinas, SP: Papirus. (Trabalho original publicado em 1989).

Skinner, B. F. (1999). The operational analysis of psychological terms. In V. G. Laties, \& A. C. Catania (Eds.), Cumulative record: definitive edition (pp. 416-430). Acton, MA: Copley. (Trabalho original publicado em 1945).

Steffens, R. A. K., Liz, C. M., Viana, M. S., Brandt, R., Oliveira, L. G. A., \& Andrade, A. (2011). Praticar caminhada melhora a qualidade do sono e os estados de humor em mulheres com síndrome da fibromialgia. Revista Dor, 12(4), 327-331. https://doi.org/10.1590/S1806-00132011000400008

\section{Bruna de Souza}

Graduada em Psicologia pela Universidade Estadual de Maringá e residente em Psicologia no programa de Residência Multiprofissional em Saúde e em Área Profissional da Saúde, ênfase na Urgência e Emergência, pela Universidade Estadual de Maringá.

E-mail: brunasouzza1994@gmail.com

\section{Carolina Laurenti}

Professora adjunta do Departamento de Psicologia da Universidade Estadual de Maringá, Centro de Ciências Humanas Letras e Artes.

E-mail: laurenticarol@gmail.com

Endereço para envio de correspondência:

Av. Colombo, 5790 - Bloco 118, sala 08. Jardim Universitário. CEP 87020-900. Maringá - PR, Brasil. 
Recebido 22/03/2016

Reformulação 07/03/2017

Aprovado 07/03/2017

Received $03 / 22 / 2016$

Reformulated $03 / 07 / 2016$

Approved 03/072017

Recebido 22/03/2016

Reformulado 07/03/2017

Aceptado 07/03/2017

Como citar: Souza, B., \& Laurenti, C. (2017). Uma interpretação molar da dor crônica na fibromialgia. Psicologia: Ciência e Profissão, 37(2), 363-377. https://doi.org/10.1590/1982-3703001102016

How to cite:Souza, B., \& Laurenti, C. (2017). Molar interpretation of chronic pain in fibromyalgia. Psicologia: Ciência e Profissão, 37(2), 363-377. https://doi.org/10.1590/1982-3703001102016

Cómo citar:Souza, B., \& Laurenti, C. (2017). Una interpretación molar del dolor crónico en la fibromialgia. Psicologia: Ciência e Profissão, 37(2), 363-377. https://doi.org/10.1590/1982-3703001102016 